\title{
Original insights on thrombospondin-1-related antireceptor strategies in cancer
}

\author{
Albin Jeanne ${ }^{1,2,3}$, Christophe Schneider ${ }^{1,2}$, Laurent Martiny ${ }^{1,2}$ and Stéphane Dedieu ${ }^{1,2 *}$ \\ ${ }^{1}$ Laboratoire SiRMa, UFR Sciences Exactes et Naturelles, Université de Reims Champagne-Ardenne, Reims, France, \\ ${ }^{2}$ CNRS, Matrice Extracellulaire et Dynamique Cellulaire, UMR 7369, Reims, France, ${ }^{3}$ SATT Nord, Lille, France
}

OPEN ACCESS

Edited by:

Stephane Germain,

Institut National de la Santé et de la Recherche Médicale, France

Reviewed by:

Jeffrey S. Isenberg,

University of Pittsburgh Schoo

of Medicine, USA

David D. Roberts,

National Institutes of Health, USA

${ }^{*}$ Correspondence:

Stéphane Dedieu

stephane.dedieu@univ-reims.fr

Specialty section:

This article was submitted to Pharmacology of Anti-Cancer Drugs,

a section of the journal

Frontiers in Pharmacology

Received: 04 September 2015 Accepted: 15 October 2015

Published: 29 October 2015

Citation:

Jeanne A, Schneider C, Martiny L and Dedieu S (2015) Original insights on thrombospondin-1-related

antireceptor strategies in cancer.

Front. Pharmacol. 6:252.

doi: 10.3389/fphar.2015.00252
Thrombospondin-1 (TSP-1) is a large matricellular glycoprotein known to be overexpressed within tumor stroma in several cancer types. While mainly considered as an endogenous angiogenesis inhibitor, TSP-1 exhibits multifaceted functionalities in a tumor context depending both on TSP-1 concentration as well as differential receptor expression by cancer cells and on tumor-associated stromal cells. Besides, the complex modular structure of TSP-1 along with the wide variety of its soluble ligands and membrane receptors considerably increases the complexity of therapeutically targeting interactions involving TSP-1 ligation of cell-surface receptors. Despite the pleiotropic nature of TSP-1, many different antireceptor strategies have been developed giving promising results in preclinical models. However, transition to clinical trials often led to nuanced outcomes mainly due to frequent severe adverse effects. In this review, we will first expose the intricate and even sometimes opposite effects of TSP-1-related signaling on tumor progression by paying particular attention to modulation of angiogenesis and tumor immunity. Then, we will provide an overview of current developments and prospects by focusing particularly on the cell-surface molecules CD47 and CD36 that function as TSP-1 receptors; including antibody-based approaches, therapeutic gene modulation and the use of peptidomimetics. Finally, we will discuss original approaches specifically targeting TSP-1 domains, as well as innovative combination strategies with a view to producing an overall anticancer response.

Keywords: TSP-1, CD47, CD46, cancer, angiogenesis, innovative therapeutic strategies

\section{STATE OF THE ART}

In view of the relatively short-lived benefits observed in targeted therapies that aim at facing advanced primary cancers, the current main therapeutic challenge is to identify original molecular targets in order to limit tumor burden without allowing resistance acquisition (van Beijnum et al., 2015). Indeed, the advent of systems biology over recent years underlined the limits of therapeutic agents designed to block a single pathway and/or growth factor, inevitably leading to the activation of compensatory mechanisms which allow tumor escape and restore disease progression (Wilson et al., 2015). To face the complexity and massive redundancy of signaling pathways and regulatory

Abbreviations: 3TSR, three thrombospondin-1 type 1 repeats; ECM, extracellular matrix; EOC, epithelial ovarian cancer; FGF-2, fibroblast growth factor-2; MET, metronomic; MTD, maximum tolerated dose; PD, pharmacodynamic; PK, pharmacokinetic; RBCs, red blood cells; SIRP $\alpha$, signal regulatory protein alpha; TCR, T cell receptor; TRAIL, tumor necrosis factor-related apoptosis-inducing ligand; TSP-1, thrombospondin-1; VEGFR2, vascular endothelial growth factor receptor 2. 
processes underlying tumor progression, growing attention is accorded to matricellular proteins and their cell receptors as they function as multiple integrators of tumor progression signals at the tumor/microenvironment interface (MurphyUllrich and Sage, 2014). According to their definition first given by Paul Bornstein 25 years ago, matricellular proteins regulate a wide range of both malignant and stromal cell functions through interactions with cell-surface receptors or by acting in a coordinated manner with other ECM components or soluble molecules (Sage and Bornstein, 1991). TSPs may be regarded as the archetypes of the matricellular protein group, with TSP-1 first identified from human platelets in 1978 (Lawler et al., 1978).

Thrombospondin-1 is considered a main actor within a tumor microenvironment, while it exerts intricate and sometimes opposite effects on tumor progression. Elevated circulating levels of TSP-1 were early observed in patients presenting breast, lung, gastrointestinal or even gynecological malignancies (Tuszynski et al., 1992; Nathan et al., 1994). In patients receiving myelosuppressive anti-cancer chemotherapy, TSP-1 blood concentrations assessments strongly correspond with platelet counts (Starlinger et al., 2010). Of note, such correlation is also observed in non-malignant processes where platelet activation is high, such as sickle cell disease (Novelli et al., 2012). Nevertheless, others have noted that elevation of circulating TSP-1 in a cancer setting could be even noticed in absence of plasma contamination by platelet activation (Byrne et al., 2007), thus suggesting that TSP-1 plasma levels might originate from sources other than platelets. Therefore, additional work is needed to determine the exact origins of high TSP-1 plasma concentrations, particularly as many non-platelet sources are known to produce TSP-1 such as endothelial cells, cancer cells, or even circulating immune cells (Dawes et al., 1988). Among the range of possibilities, tumor-originating TSP-1 may provide a plausible explanation to elevated levels detected in patients. Indeed, increased TSP-1 mRNA and/or protein levels were observed within the stromal compartment of breast and gastric carcinoma (Clezardin et al., 1993; Brown et al., 1999; Lin et al., 2012). On the contrary, carcinoma cells express undetectable to low levels of TSP1 in these studies, and loss of TSP-1 expression by cancer cells is described as an important feature of the "angiogenic switch" in a wide range of solid tumors (Naumov et al., 2006). Indeed, TSP-1 expression is typically down-regulated by oncogenes whereas it is promoted by tumor suppressor genes such as p53 (Dameron et al., 1994). Recently, oncogenic Ras was confirmed as being likely to induce phosphorylation of Myc, thus leading to TSP-1 repression and acquisition of an angiogenic phenotype (Watnick et al., 2015). While TSP-1 expression is lost during malignant progression in a wide variety of major cancer types, a few exceptions need nevertheless to be considered. By way of example, TSP-1 is over-expressed by invasive and metastatic melanoma cells, in which it actively contributes to an epithelial-to-mesenchymal transition program (Jayachandran et al., 2014; Borsotti et al., 2015).

Like other matricellular proteins, TSP-1 is a multi-modular and multifunctional protein able to bind a wide variety of ligands, thus considerably increasing the complexity of its translational potential. As a consequence, it seems obvious that strategies blindly targeting a specific function such as gross matricellular protein silencing, or the use of blocking antibodies, may induce severe adverse effects. Indeed the beneficial properties of the multifunctional protein may also be lost under such treatment. Here, we will focus on TSP-1 and two of its receptors viz. CD47 and CD36, to review pre-clinical and clinical outcomes that could be achieved with current developments. Then, we will discuss future directions to target these cell-surface receptors, using small molecules and peptides able to interfere with TSP-1/CD47 as well as TSP-1/CD36 signaling axis in order to reach an overall anticancer response.

\section{TSP-1: A MAIN ACTOR WITHIN TUMOR MICROENVIRONMENT}

Thrombospondin-1 has long been considered to play a role in tumor progression; several studies carried out 20 years ago found it to be overexpressed within tumor stroma and in high circulating levels in several cancers (Qian and Tuszynski, 1996; Bertin et al., 1997; Brown et al., 1999). TSP-1 was also reported to contribute to metastatic spread by promoting tumor cell emboli formation (Incardona et al., 1995). In recent years, an increasing number of studies have tended to present TSP-1 as a poor prognosis and recurrence marker in many cancer types including glioma (Perez-Janices et al., 2015), melanoma (Borsotti et al., 2015) as well as ovarian and pancreatic carcinomas (Lyu et al., 2013; Nie et al., 2014; Pinessi et al., 2015). Among TSP-1 ligands, CD36 and CD47 cell-surface receptors act as key integrators of multiple signals regulating tumor growth and dissemination both positively and negatively. Indeed, TSP$1 / C D 36 / C D 47$ trimolecular signaling platform dynamics as well as interactions involving co-receptors and soluble ligands exert pleiotropic activities on cancer progression, by directly modulating cancer cells behavior or by acting on tumor microenvironment stromal cells (Kazerounian et al., 2008; Sick et al., 2012).

\section{Modulation of Angiogenesis by TSP-1}

Thrombospondin-1 is widely known as an endogenous inhibitor of angiogenesis by negatively regulating $\mathrm{NO}$-mediated signaling in endothelial cells, vSMC and platelets (Isenberg et al., 2008a, 2009b). TSP-1 inhibition of NO/cGMP-related pathways and subsequent antiangiogenic activities are mediated by its interaction with two cell-surface receptors: CD47 and CD36 (Isenberg et al., 2009c; Zhang et al., 2009). CD47 is a ubiquitous $50 \mathrm{kDa}$ receptor consisting of a single $\mathrm{N}$-terminal $\mathrm{IgV}$ extracellular domain, five membrane-spanning segments and a short C-terminal cytoplasmic tail (Sick et al., 2012). Although it is now commonly referred to by its immunological marker name, CD47 receptor was first identified through its association with $\alpha_{V} \beta_{3}$ integrin, therefore justifying its former name IAP (integrin associated protein; Brown et al., 1990). At the same time, the ovarian tumor antigen OA3 was characterized (Campbell et al., 1992) and subsequently shown to be the 
same protein as CD47 (Mawby et al., 1994). CD47 is widely considered as a marker of "self," and is therefore highly expressed by circulating hematopoietic stem cells, erythrocytes and many malignant cells (Oldenborg et al., 2000; Jaiswal et al., 2009). Notably, CD47 was described as a marker of tumor-initiating cells in leukemia as well as in bladder and liver cancer (Chan et al., 2009; Willingham et al., 2012a; Lee et al., 2014). In cancer, CD47 acts as a "don't eat me" signal by engaging its macrophage phagocytic counter-receptor SIRP $\alpha$ (signal regulatory protein alpha; Vernon-Wilson et al., 2000; Chao et al., 2012). Thus, CD47 binding to SIRP $\alpha$ present on immune cells causes a dephosphorylation cascade avoiding synaptic myosin accumulation and thereby preventing engulfment (Tsai and Discher, 2008). However, broad evidence now sustains that CD47 signaling functions go well beyond this simple antiphagocytic passive role, with CD47 acting as a sensor for cell-cell and cell-microenvironment signals. Indeed SIRP $\alpha$ can interact with CD47 receptors in cis or in trans, and CD47/SIRP $\alpha$ signaling should not be considered as unidirectional in so far as SIRP $\alpha$ binding can in turn affect intracellular signaling through CD47 (Latour et al., 2001), which has further been called "reverse" signaling (Sarfati et al., 2008). While this provides an exciting area for future research, numerous studies of CD47 signaling functions that have been published so far focused on CD47 activation by TSP-1. Indeed, TSP-1 available within the ECM is a key regulator of CD47 signaling. CD47 ligation by TSP1 C-terminal domain dissociates its constitutive association with VEGFR2 and allows inhibition of both early eNOSactivating signals and NO-independent VEGFR2 signaling, thus leading to subsequent antiangiogenic responses (Kaur et al., 2010; Soto-Pantoja et al., 2015). Remarkably, TSP-1:CD47 interaction also redundantly inhibits NO signaling at the level of such downstream effectors as soluble guanylate cyclases (sGC; Isenberg et al., 2006) and cGMP-dependent protein kinases (cGK; Isenberg et al., 2008a,c). Of note, co-immunoprecipitations experiments were recently conducted identifying for the first time TSP- 1 as a new ligand for $\operatorname{SIRP} \alpha$, which may result in stimulation of SIRP $\alpha$ phosphorylation and downstream signaling in non-phagocytic cells (Yao et al., 2014). While this process is likely to involve the joint contribution of $\mathrm{CD} 47$, it raises the exciting likelihood of a CD47-independent SIRP $\alpha$ signaling under TSP-1 ligation. As cell-free binding assays indicated that TSP-1:SIRP $\alpha$ interaction does not imply the C-terminal domain of TSP-1, further studies considering recombinant fragments as well as molecular docking experiments would be of particular interest to better characterize this newly identified interaction. To further increase the complexity of TSP-1/CD47/SIRP $\alpha$ signaling axis, it has to be noted that both CD47 and SIRP $\alpha$ ectodomains could be target of sheddases and thus provide additional ligands for TSP-1, CD47, and SIRPa (Ohnishi et al., 2004; Maile et al., 2008; Toth et al., 2013).

In addition to $\mathrm{CD} 47$-induced effects, a central region of TSP- 1 called 3TSR (three TSP- 1 type 1 repeats) binds itself to the CD36 membrane receptor, also leading to angiogenesis inhibition. CD36, first identified from platelets as glycoprotein IV (GpIV; Clemetson et al., 1977), is a class B scavenger receptor (Calvo et al., 1995) also acting as fatty acid translocase (Pohl et al., 2005). It is mostly expressed by microvascular endothelial cells and vSMC (Dawson et al., 1997; Silverstein and Febbraio, 2009) in which TSP-1 ligation promotes CD36 association with $\beta 1$ integrin and VEGFR2 dimer in a tripartite complex, resulting in decreased VEGFR2 phosphorylation under VEGF stimulation (Zhang et al., 2009). Besides, TSP-1 binding to CD36 inhibits NO-related signaling at the level of eNOS by preventing myristate uptake and also its downstream effects. Indeed, both TSP- 1 and a peptide derived from the 3TSR as well as a CD36 "agonist" mAb are able to modulate the fatty acid translocase activity of CD36 by preventing myristate uptake in vascular cells (Isenberg et al., 2007). As CD36 is expected to be the main cell membrane protein involved in fatty acid uptake (Koonen et al., 2005), one should bear in mind that targeting this receptor may affect lipoprotein and glucose metabolism, and therefore lead to cardiovascular complications. In humans, CD36 deficiency is associated with phenotypic expression of the "metabolic syndrome," i.e., hypercholesterolemia, hyperglycemia, insulin resistance, and higher blood pressure (Hirano et al., 2003). Besides, TSP-1 and TSP-1-derived agents that inhibit myristate uptake through CD36 activation are also likely to affect non angiogenesis-related signaling pathways as post-translational myristoylation regulates many protein and cell functions (Martin et al., 2011). While TSP-1 is a high affinity ligand for CD47, binding to CD36 requires higher concentrations that overcome physiological levels. Apart from this 100 -fold difference in binding affinities, results from null cells and animals also indicate that while TSP-1 ligation of either CD36 or CD47 is sufficient to inhibit NO-stimulated vascular responses, only CD47 is necessary for such TSP-1 activity at physiological concentrations (Isenberg et al., 2006). However, considering that TSP-1 protein levels in tumor and surrounding tissue are found to be elevated in several cancers (for review, see Kazerounian et al., 2008), one can assume that CD36-activating concentrations are reached within a tumor microenvironment.

\section{TSP-1 Direct Impact on Cancer Cell Behavior and Tumor Immunity}

Far from being restricted to angiogenesis modulation, the effects of TSP-1 on tumor progression are multifaceted and sometimes even opposite depending on the molecular and cellular composition of the microenvironment. Indeed, its ability to interact with multiple ligands enables TSP-1 to regulate a wide range of processes such as tumor cell adhesion (Li et al., 2006), proliferation (Sick et al., 2011), survival or apoptosis (Manna and Frazier, 2004; Saumet et al., 2005; Rath et al., 2006a,b), tumor invasion and metastatic dissemination (Jayachandran et al., 2014; Borsotti et al., 2015), inflammation, immune response (Grimbert et al., 2006) and response to treatment (Lih et al., 2006; Bi et al., 2014). Such pleiotropic effects may be governed by TSP-1 concentration as well as by its origin, whether it originates from tumor cells or the stroma compartment (Pinessi et al., 2015). Reverse responses may also be observed depending on the cancer type. For instance, CD47 ligation by TSP- 1 induces killing of breast cancer cells (Manna and Frazier, 2004) while it was reported to inhibit apoptosis 
and promote drug resistance in thyroid carcinoma cells (Rath et al., 2006a,b). Besides, TSP-1 can also trigger cancer cell death by interacting with the CD36 receptor as recombinant 3TSR fragments of TSP-1 were shown to inhibit proliferation and to induce apoptosis of murine epithelial ovarian cancer cells (EOC; Russell et al., 2015). Therefore, TSP-1 effects on malignant cells are dependent on receptor expression profiles that are likely to vary between different malignant subpopulations or even depending on their differentiation degrees (Zheng et al., 2015).

Apart from TSP-1-related direct modulation of cancer cell behavior through interactions with membrane receptors, the TSP-1/CD47/SIRP $\alpha$ axis is also strongly implicated in controlling tumor immunity, with both positive and negative roles. A widely held opinion is that tumor cells express high CD47 levels to inhibit phagocytosis by signaling through SIRP $\alpha$ found on macrophages and dendritic cells (DCs; Zhao et al., 2011; Chao et al., 2012; Willingham et al., 2012a). Accordingly, restoration of CD47 expression in CD47-deficient leukemia cells increases xenograft aggressiveness (Jaiswal et al., 2009). To date, CD47/SIRP $\alpha$ is the only known negative regulator of phagocytosis at the immunological synapse and it is known to play an important physiological role in maintaining hematopoietic cells and platelets homeostasis (Olsson et al., 2005; Sick et al., 2012). In addition, CD47:SIRP $\alpha$ interaction may also indirectly promote tumor dissemination through binding of tumor cells to macrophages that reside at the level of potential extravasation sites within the vascular wall (Chao et al., 2011b). Several structural and mutagenesis studies highlighted that according to their respective spatial configuration within CD47 extracellular domain, the TSP-1 and SIRP $\alpha$ interaction sites may not be redundant (Floquet et al., 2008; Hatherley et al., 2008; Jeanne et al., 2015; Soto-Pantoja et al., 2015). However, direct binding assays provided contradictory evidence as both TSP-1 and a function-blocking CD47 antibody inhibit CD47:SIRP $\alpha$ interaction (Isenberg et al., 2009a). Furthermore, recent studies underlined that TSP-1 may also interact with SIRP $\alpha$ (Yao et al., 2014), thus accentuating the impression that the above-mentioned studies asserting an essential contribution of the CD47:SIRP $\alpha$ "don't eat me" signal remains incomplete, especially as none of this work was done controlling the absence or presence of TSP-1.

Aside from the previously exposed modulation of innate immunity by the CD47/SIRP $\alpha$ antiphagocytic axis, TSP1 interaction with CD47 existing on immune cells mostly inactivates antitumor adaptive immunosurveillance. Indeed TSP1 was shown to directly inhibit TCR-mediated T cell activation (Li et al., 2001) by engaging CD47 (Li et al., 2002). Secreted TSP-1 that binds CD47 on T cells inhibits both the NO/cGMP pathway (Ramanathan et al., 2011) and $\mathrm{H}_{2} \mathrm{~S}$ signaling (Kaur et al., 2015), therefore concomitantly resulting in an homeostatic inhibitory role of TSP-1:CD47 interaction on T-cell activation. On the other hand, there are cross-talks between the above described mechanisms and VEGF signaling in T cells. Thus, CD47 ligation by TSP-1 inhibits VEGFR2 phosphorylation hence limiting VEGF-induced inhibition of $\mathrm{T}$ cell proliferation and TCR signaling (Kaur et al., 2014). Otherwise, TSP-1 binding to $\mathrm{CD} 47$ also inhibits differentiation of naïve $\mathrm{T}$ cells into Th1 (Bouguermouh et al., 2008), whereas Tregs formation is induced by promoting Foxp3 transcription factor expression (Grimbert et al., 2006; Baumgartner et al., 2008). In cancer, CD47 blockade was shown to enhance antitumor immunity by stimulating CD8+ cytotoxic T cells (Soto-Pantoja et al., 2014). In combination with ionizing radiotherapy that enhances $\mathrm{T}$ cell antitumor immunity (Demaria and Formenti, 2012), CD47 blockade in effector $\mathrm{T}$ cells is therefore sufficient to inhibit tumor growth, thus offsetting the widely spread opinion that CD47 blockade anticancer effects are attributed to phagocytosis of cancer cells by macrophages. CD47 signaling also regulates natural killer (NK) and DC functions that orchestrate adaptative immunity, leading to tolerogenic signals toward tumor under TSP-1 ligation (Kim et al., 2008; Weng et al., 2014).

Considering these contradictory data, one should realize that TSP-1 roles in cancer progression and metastatic dissemination are complicated and intricate, often leading to paradoxical signals. Indeed, for the purpose of designing new therapeutics, one should bear in mind that several ECM soluble factors and/or cell-surface receptors could bind simultaneously and act as competitors, or even allosterically influence each other's binding and signaling. Therefore, it seems obvious that TSP1 and/or its receptors massive blockade or silencing may lead to inevitable adverse effects, closely related to the pleiotropic nature of matricellular proteins and their ligands. Despite these considerations, a few strategies have shown promising results in animal cancer models and some of them already moved to clinical trials.

\section{THERAPEUTIC TARGETING OF TSP-1-RELATED SIGNALING}

Therapeutic strategies targeting TSP-1 signaling and its CD47/CD36 membrane receptors have already been extensively reviewed over the last 5 years (Belotti et al., 2011; Henkin and Volpert, 2011; Sick et al., 2012; Soto-Pantoja et al., 2013b). Thereby, this review is not meant as a comprehensive overview, but rather as a snapshot of current pre-clinical to clinical developments. The range of new therapeutic methods support the sharply expanding interest in targeting TSP-1-related signaling with a view to regulating its function during cancer progression. After describing the most advanced strategies (summarized in Table 1) as well as their benefits and limitations, we will discuss more original and sophisticated approaches which aim at modulating TSP-1/CD47/CD36 signalization either directly or indirectly in order to provide an overall anticancer response. Then we will consider future directions and treatment optimizations with the objective of improving further clinical outcomes.

\section{Antibody Blockade and Gene Therapeutics}

The use of monoclonal antibodies (mAbs) is an obvious way to therapeutical target cell-surface receptors. Considerable efforts 
TABLE 1 | Therapeutic strategies targeting TSP-1-related signaling.

\begin{tabular}{|c|c|c|c|c|}
\hline Compound & Origin/sequence & Target & Stage & Reference \\
\hline $\begin{array}{l}\text { CD47-blocking } \\
\text { mAb }\end{array}$ & & CD47 & Phase 1 & $\begin{array}{l}\text { clinicaltrials.gov (four trial studies } \\
\text { ongoing) }\end{array}$ \\
\hline $\begin{array}{l}\text { CD47 antisense } \\
\text { morpholino }\end{array}$ & & $\mathrm{CD} 47$ & Pre-clinic & Maxhimer et al., 2009 \\
\hline \multicolumn{5}{|l|}{ Peptides } \\
\hline $4 \mathrm{~N} 1 / 4 \mathrm{~N} 1-\mathrm{K}$ & TSP-1 (K-RFYVMWK-K) & CD47 & Pre-clinic & Kalas et al., 2013 \\
\hline $7 \mathrm{~N} 3$ & TSP-1 (FIRVVMYEGKK) & CD47 & In vitro & Maxhimer et al., 2009 \\
\hline PKHB1 & $\begin{array}{l}\text { i.e., } 4 \mathrm{~N} 1 \mathrm{~K} \text {, with } \mathrm{D} \text { counterparts } \\
\text { for } \mathrm{N} \text { - and } \mathrm{C} \text {-terminal lysines }\end{array}$ & $\mathrm{CD} 47$ & Pre-clinic & Martinez-Torres et al., 2015 \\
\hline TAX2 & CD47 (CEVSQLLKGDAC) & TSP-1 & Pre-clinic & Jeanne et al., 2015 \\
\hline $\begin{array}{l}\text { Psap-derived } \\
\text { peptide }\end{array}$ & Prosaposin (DWLPK) & $\begin{array}{l}\text { TSP-1 } \\
\text { upregulation in } \\
\text { Gr1 }^{+} \text {cells }\end{array}$ & Pre-clinic & Catena et al., 2013 \\
\hline $\begin{array}{l}\text { TSP-1 } \\
\text { recombinant } \\
\text { fragment }\end{array}$ & TSP-1 & & & \\
\hline 3TSR & Type 1 repeats & CD36 & Pre-clinic & Zhang et al., 2005 \\
\hline $\begin{array}{l}\text { 3TSR/TRAIL fusion } \\
\text { protein }\end{array}$ & Type 1 repeats, TRAIL & $\begin{array}{l}\text { CD36 and } \\
\text { TRAIL receptor }\end{array}$ & Pre-clinic & Choi et al., 2015 \\
\hline \multicolumn{5}{|l|}{ Peptidomimetics } \\
\hline ABT-526 (Abbott) & TSP-1 type 1 repeats (GVITRIR) & CD36 & Pre-clinic & Rusk et al., 2006 \\
\hline ABT-510 (Abbott) & TSP-1 type 1 repeats (GVITRIR) & CD36 & Phase 2 & Baker et al., 2008 \\
\hline ABT-898 (Abbott) & TSP-1 type 1 repeats (GVITRIR) & CD36 & Pre-clinic & Campbell et al., 2011 \\
\hline CVX-022 (Pfizer) & TSP-1 mimetic + scaffold Ab & CD36 & Pre-clinic & Coronella et al., 2009 \\
\hline CVX-045 (Pfizer) & TSP-1 mimetic + scaffold Ab & CD36 & Phase 1 & Molckovsky and Siu, 2008 \\
\hline \multicolumn{5}{|c|}{ Non-peptide small molecule } \\
\hline sm27 & TSP-1 type 3 repeats & FGF-2 & Pre-clinic & Taraboletti et al., 2010 \\
\hline \multicolumn{5}{|l|}{ Others } \\
\hline $\begin{array}{l}\text { Trabectedin } \\
\text { (ET-743, Yondelis) }\end{array}$ & Marine natural product & $\begin{array}{l}\text { TSP-1 } \\
\text { upregulation by } \\
\text { tumor cells }\end{array}$ & Approved & Monk et al., 2012; Dossi et al., 2015 \\
\hline $\begin{array}{l}\text { Velcro-CD47 } \\
\text { (N3612) }\end{array}$ & CD47 extracellular domain & $\operatorname{SIRP} \alpha$ & In vitro & Ho et al., 2015 \\
\hline
\end{tabular}

have focused on developing CD47-targeting mAbs to block the CD47/SIRP $\alpha$ antiphagocytic pathway established between tumor cells and immune cells. Such CD47-blocking mAbs were shown to be effective by allowing the decrease of tumor burden in several preclinical cancer models including acute myeloid leukemia (Majeti et al., 2009), lymphoma (Chao et al., 2010) and osteosarcoma (Xu et al., 2015). While the decrease in tumor growth is mainly attributed to enhanced tumor cell clearance by macrophages under CD47:SIRP $\alpha$ disruption (Willingham et al., 2012a), other studies have noted that alternative mechanisms may explain the antitumor activities of CD47-blocking antibodies. Particularly, the use of intact IgG (such as B6H12 anti-CD47 $\mathrm{Ab}$ ) in the previously mentioned in vivo experiments may also induce Fc-mediated cytotoxicity (Zhao et al., 2011). Of note, one of the CD47-blocking antibody that reduced tumor growth (clone miap410; Willingham et al., 2012b) raised doubts as to its ability to block CD47:SIRP $\alpha$ interaction (Han et al., 2000; Willingham et al., 2012b). Altogether, these data suggest that increased macrophage phagocytosis is not sufficient to explain antitumor activities of CD47-targeting mAbs and that other actors are involved (Soto-Pantoja et al., 2012a; Zhao et al.,
2012). Particularly, in vitro and in vivo studies have shown that macrophages are able to prime an effective CD8 $+\mathrm{T}$ cell response following anti-CD47 treatment-mediated phagocytosis of cancer cells, by concomitantly inducing a reduction in regulatory $\mathrm{T}$ cell population (Tseng et al., 2013). To date, at least four first-inman phase 1 clinical trials considering anti-CD47 humanized mAbs are underway, according to clinicaltrials.gov website (identifiers NCT02216409, NCT02447354, NCT02488811, and NCT02367196). Given the ubiquitous expression of CD47, systemically administered anti-CD47 mAbs will inevitably come across a huge number of CD47 copies on red blood cells (RBCs). To avoid phagocytic-induced excessive reduction in erythrocytes count, it has been suggested to use a primingdose of anti-CD47 that would result in "aged" RBCs removal and subsequent erythropoiesis stimulation (McCracken et al., 2015). Such suggestion is obviously questionable, as many other clearance mechanisms are known to be preponderant in triggering removal of senescent RBCs (Lutz and Bogdanova, 2013). One should note that experiments considering CD47 targeting agents in mice did not induce any significant anemia, which also runs counter to a major role for antiphagocytic 
"don't eat me" signal disruption in these studies. Besides, CD47 plays fundamental physiological roles by limiting NO signaling in RBCs, platelets, and endothelium (Soto-Pantoja et al., 2015). Indeed, CD47 antibody targeting may affect NO pathway modulation and subsequent angiogenesis regulation, since a commonly used CD47-blocking antibody (clone B6H12) was previously shown to concomitantly disrupt both TSP1:CD47 and CD47:SIRP $\alpha$ interactions (Isenberg et al., 2009a). As pre-clinical data suggests that high circulating TSP-1 levels produced by tumor stroma may indirectly increase tumor perfusion while decreasing peritumoral and systemic blood flow, CD47-targeting mAbs are therefore likely to counteract these effects through regional stimulation of NO signaling (Isenberg et al., 2008b, 2009b). On the other hand, anti-CD47 antibodies may also interfere with CD36-mediated modulation of NO signaling, as CD47 is required for $\mathrm{CD} 36$ activation under TSP-1 ligation (Isenberg et al., 2006). According to this, systemic administrations of anti-CD47 mAbs for cancer treatment would probably lead to severe adverse events such as hypertension and thrombosis. Therefore, we are not fully persuaded by the use of $\mathrm{CD} 47$ antibodies as an alternative to current anticancer drugs, while their local use is much more promising for instance in ischemia prevention (Lin et al., 2014).

As RBCs have prolonged circulating lifetimes without any membrane protein turnover (Mohandas and Gallagher, 2008), other groups have suggested that acute genetic modulation of CD47 expression may represent a surrogate to some of the antibody-based strategies side-effects. Indeed CD47 antisense morpholino potently reduced tumor burden in patient-derived hepatocellular carcinoma xenografts (Lee et al., 2014). This study highlighted that the use of morpholino against CD47 mRNA may be of particular interest in combination with conventional chemotherapy as it potentialized the effects of doxorubicin. In the context of syngeneic melanoma allografts, morpholino suppression of CD47 expression induced only a modest decrease of tumor growth (Maxhimer et al., 2009). There again, more beneficial effects were reached when combining morpholino treatment with radiotherapy in the same allograft model. It should be noted that similar inhibition of tumor growth is observed when irradiating TSP-1 null mice, thus suggesting that anticancer targeting of TSP-1:CD47 interaction would be of a greater relevance than disrupting CD47:SIRP $\alpha$ (Isenberg et al., 2008c; Soto-Pantoja et al., 2013b). Accordingly, TSP-1 silencing in DCs by shRNA interference exhibited antitumor effects in a bladder cancer syngeneic model, by increasing tumor-infiltrating CD4+ and CD8+ T cells (Weng et al., 2014). There again, TSP1 wide-spread silencing may be a double-edged sword for cancer therapy as TSP-1 exerts opposite effects in endothelial cells and DCs. Therefore, the use of TSP-1 recombinant fragments or small antagonistic molecules may be of a better interest.

\section{TSP-1-derived Peptides, Recombinant Fragments, and Mimetics}

Several synthetic peptides derived from the C-terminal domain of TSP-1 were early identified as containing a critical VVM motif proposed to be essential for CD47 binding (Gao and Frazier, 1994). Among them, the widely used 4N1 $\left({ }^{1016}\right.$ RFYVVMWK $\left.{ }^{1024}\right)$ and 7 N3 $\left({ }^{1102}\right.$ FIRVVMYEGKK $\left.{ }^{1112}\right)$ are able to reproduce some of TSP-1-mediated biological effects in in vitro models (Rath et al., 2006a; Maxhimer et al., 2009). However, $4 \mathrm{~N} 1$ should no longer be considered as a CD47-specific targeting agent as several studies pointed out 15 years ago its ability to induce cellular responses in a CD47-independent fashion (Tulasne et al., 2001; Barazi et al., 2002). In addition, there is a dearth of convincing in vivo data concerning these peptides, probably due to moderate affinity to CD47 and poor pharmacokinetic properties, thus requiring high dose treatments. Indeed repeated administrations of an extended version of the $4 \mathrm{~N} 1$ peptide named $4 \mathrm{~N} 1 \mathrm{~K}$ (K${ }^{1016}$ RFYVVMWK ${ }^{1024}-\mathrm{K}$ ) induce only modest changes in tumor growth (Kalas et al., 2013), while $4 \mathrm{~N} 1 \mathrm{~K}$ exhibits low stability in plasma. Consideration of $4 \mathrm{~N} 1 \mathrm{~K}$ as a $\mathrm{CD} 47$ agonist is all the more controversial as its VVM motif is actually buried within a hydrophobic $\beta$-strand arrangement of C-terminal TSP1 , therefore, avoiding accessibility to CD47 without significant conformational changes (Kvansakul et al., 2004). However, normal mode analysis and energy minimizations helped to identify large amplitude motions of TSP-1 signature domain, leading to opening of the hydrophobic cleft and allowing solvent exposure of the $4 \mathrm{~N} 1$ sequence (Floquet et al., 2008). Some studies highlighted differences in $4 \mathrm{~N} 1 \mathrm{~K}$-induced responses between CD47+/+ and CD47-/- cells or considering CD47 blocking mAbs (Fujimoto et al., 2003; McDonald et al., 2004), which remains unexplained in view of the above-mentioned studies demonstrating 4N1 non-specificity. Despite these considerations, others have suggested that some of the in vitro effects of $4 \mathrm{~N} 1 \mathrm{~K}$ are likely to be due to its hyper-adhesive nature rather than its interaction with CD47, particularly as CD47-deficient cells are able to bind immobilized $4 \mathrm{~N} 1 \mathrm{~K}$ (Leclair and Lim, 2014). Interestingly, a recently identified serum-stable analog of $4 \mathrm{~N} 1 \mathrm{~K}$ named PKHB1, in which natural L-amino acids are replaced by their D counterparts, was demonstrated to induce a twofold reduction in human chronic lymphocytic leukemia xenografts growth (Martinez-Torres et al., 2015). Nevertheless, caution should be observed about such TSP1-derived CD47 agonists as they might also induce adverse inhibitory effects on host DCs immunity (Weng et al., 2014).

Among TSP-1 multiple domains, the main antiangiogenic sequences are thought to reside within the type 1 repeats involved in CD36 binding (Belotti et al., 2011). Indeed recombinant 3TSR fragments potently inhibit tumor growth in both syngeneic melanoma and orthotopic human pancreatic carcinoma models (Miao et al., 2001; Zhang et al., 2005). Subsequently, TSP-1derived peptidomimetics were developed and even reached phase 2 clinical trials. ABT-526 (Abbott Laboratories) was the first to be described as a modified peptide based on the GVITRIR sequence of the second TSP-1 type 1 repeats (Haviv et al., 2005), and yield impressive disease regression without any significant adverse effects in tumor-bearing dogs (Rusk et al., 2006). Thereafter a more soluble enantiomer with better PK/PD profile, named ABT-510, entered clinical trials. After showing 
relevant PK properties in phase 1 trials (Hoekstra et al., 2005; Gietema et al., 2006), ABT-510 failed to give clear evidence of efficacy in phase 2 and led to severe adverse events such as thrombosis and pulmonary embolism (Ebbinghaus et al., 2007; Baker et al., 2008). ABT-510 is consequently no longer tested in clinical development, however, a second-generation mimetic named ABT- 898 has recently emerged with improved therapeutic activity in dogs with soft tissue sarcoma (Sahora et al., 2012). While ABT-898 treatment efficiently allowed the regression of established ovarian tumors in mice (Campbell et al., 2011), it has not entered human development so far. Conjointly, CVX-22 and CVX-045 (Pfizer) were developed fusing TSP-1-derived peptidomimetics with a proprietary scaffold antibody (Levin et al., 2007; Coronella et al., 2009). While CVX-045 showed efficacy in tumor xenografts by reducing MVD and increasing necrotic cores (Li et al., 2011), only limited benefits were observed during phase 1 clinical trials in association with severe adverse events (Molckovsky and Siu, 2008), which probably explains why such "peptibodies" have been discontinued from Pfizer pipeline in 2014 (Rader, 2014).

\section{Original Strategies and Current Developments}

Aside from peptidomimetics based on sequences from the type 1 repeats, sm27 is a non-peptide small molecule mimicking the FGF-2 binding site located in the type 3 repeats of TSP1 (Taraboletti et al., 2010) that exhibits in vitro and ex vivo antiangiogenic properties (Colombo et al., 2010). Since 2010, several computational studies have been conducted aiming to optimize sm27:FGF-2 binding dynamics (Pagano et al., 2012; Meli et al., 2014), and newly designed derivatives will presumably be evaluated in vivo in future experiments. More recently, we characterized a cyclic peptide derived from CD47, named TAX2, that directly binds TSP-1 to antagonize TSP-1:CD47 interaction (Jeanne et al., 2015). TAX2 administration led to a decrease in viable tumor volume in melanoma allograft and potently inhibited pancreatic carcinoma xenograft growth, together with a disruption of tumor-associated vascular network. In vitro studies using $\mathrm{CD} 36$ blocking $\mathrm{mAbs}$ indicated that the unpredicted antiangiogenic properties of TAX2 are likely to be mediated by CD36 activation. According to the TAX2 proposed mechanism of action, such peptide may induce a TSP-1 binding switch from CD47 to CD36. Appropriately, TAX2 antitumor effects are consistent with those observed using TSP-1 recombinant fragments targeting CD36 in similar experimental models (Miao et al., 2001; Zhang et al., 2005). The use of recombinant 3TSR as a CD36-activating treatment recently showed promising results in preclinical models of glioblastoma and ovarian carcinoma (Choi et al., 2015; Russell et al., 2015), therefore it seems relevant to assess the therapeutic potential of TAX2 in the context of such pathologies. In addition, ABT-898 was shown to be especially potent in the female reproductive tract (Campbell et al., 2011), and CD47 was early considered as an ovarian tumor marker (Campbell et al., 1992). Through its original mechanism of action which supposes concomitant disruption of TSP-1:CD47 interaction and enhancement of CD36 activation by TSP-1, TAX2 may inhibit tumor progression while limiting many of the undesired side effects of broadly inhibiting important physiological functions of CD47. Indeed, as TAX2 was designed to target TSP-1 specifically at the CD47 binding site, both TSP-1 and CD47 are presumed to remain free to interact with their respective alternative ligands. Nevertheless, some putative side-effects of using TAX2 as an anti-cancer agent still need to be explored, particularly as TSP-1 interaction with CD47 and/or CD36 is also known to modulate platelet aggregation (Isenberg et al., 2008d). While ABT-510 lack of efficacy in clinical trials is likely due to its inability to mimic the activity of full-length TSP-1 (Ebbinghaus et al., 2007; Markovic et al., 2007), we are convinced that original strategies, viz. the use of TAX2 or the identification of new inhibitors that would target pathway leading to TSP-1 repression, may provide realistic treatment alternatives by finely controlling full-length protein signaling. Interestingly, TAX2 was shown to inhibit endothelial cell cGMP production under NO stimulation. According to our assumptions, TAX2 may target the NO/cGMP pathway downstream from eNOS through stimulation of TSP-1:CD36 interaction. Hence, unlike bevacizumab or other VEGF-targeting blockbuster drugs, TAX2 may also inhibit downstream signals resulting from angiogenic signals other than VEGF such as NO production by stromal cells (Roberts et al., 2007). Currently, further work is being done to improve TAX2 translational potential.

Other molecules were also shown to cause an overall anticancer response by involving the action of TSP- 1 . Indeed trabectedin (ET-743, Yondelis), a marine natural product approved as a second-line treatment of recurrent ovarian cancer (Monk et al., 2012), exhibits antiangiogenic activities by upregulating tumor cell expression of TSP1 (Dossi et al., 2015). Besides, a five-amino acid peptide derived from prosaposin (DWLPK) was recently shown to inhibit lung metastatic colonization through upregulation of TSP-1 in $\mathrm{Grl}^{+}$myeloid cells (Catena et al., 2013). Therefore, direct stimulation of TSP-1 or even strategies that indirectly increase bioavailable TSP-1 within the pulmonary microenvironment could therefore represent a relevant translational antimetastatic approach. However, attenuation of $\mathrm{NO}$ and activated CD47 corroborate with pulmonary hypertension (Xu et al., 2004; Bauer et al., 2012) while TSP1 is a characteristic component of coronary atherosclerotic plaques (Riessen et al., 1998). Therefore, inducing TSP-1 may lead to cardiovascular complications, especially in the lung (Rogers et al., 2014). In addition, caution should be exercised in generalizing the benefits in other host organs, as they might be dependent on the cytokine environment. Particularly, Lee and collaborators reported that ADAMTS1mediated processing of TSP1 into antiangiogenic fragments occurs differently for liver and lung metastases (Lee et al., 2010).

Besides the above-described TSP-1-related therapeutic strategies, much has also been done to propose alternative methods to target CD47/SIRP $\alpha$ signaling. While current 
approaches have principally targeted the ubiquitously expressed CD47, thus inevitably leading to off-target effects, a novel engineering development has recently emerged aiming to target SIRP $\alpha$ specifically. The so-called "Velcro-CD47" (N3612) consists of a high affinity variant of the human CD47 extracellular domain extended at the N-terminus with a short three aminoacid peptide in order to increase binding affinity to $\operatorname{SIRP} \alpha$ (Ho et al., 2015). Velcro-CD47 already proved its ability to enhance macrophage phagocytosis of tumor cells in vitro and to target the monocyte subpopulation specifically, and its putative anticancer efficacy will be further evaluated in pre-clinical models.

\section{Future Directions}

In order to reach an optimal control of tumor progression, future directions will aim to associate innovative approaches targeting TSP-1/CD47 and TSP-1/CD36 signaling with existing anticancer treatments. Indeed morpholino suppression of CD47 expression was shown to markedly increase radiationinduced delay in tumor growth considering two syngeneic models of melanoma and squamous cell carcinoma (Maxhimer et al., 2009; Ridnour et al., 2015). While it sensitizes the tumor to ionizing radiation, CD47 deficiency concomitantly confers radioprotection to normal tissues through activation of autophagy (Soto-Pantoja et al., 2012b). This may be of particular interest in the field of blood cancer treatment with the aim of minimizing the adverse effects of total body irradiation, especially as morpholino-induced CD47 gene silencing was demonstrated to preserve circulating peripheral blood cells and to protect gastrointestinal tissue from ionizing radiation (SotoPantoja et al., 2013a). Therefore, future studies will determine the appropriate strategies targeting CD47 with the purpose of radiomitigation, with the potential of being translated into clinical practice.

CD36-activating 3TSR treatment efficacy was also evaluated on top of conventional chemotherapy. While intermittent bursts of MTD chemotherapy are currently considered in the treatment of ovarian cancer, combination with 3TSR may facilitate the uptake of drugs delivered at low-dose MET scheduling in order to reach higher tumor regression rates in patients with advanced EOC (Russell et al., 2015). Indeed combination of 3TSR with carboplatin and paclitaxel MET chemotherapy considerably promotes survival in a syngeneic murine model of EOC. Interestingly, 3TSR is more effective than ABT-598 in this model, thus supporting the concept that the full function of the type 1 repeats cannot be mimicked by a single short peptide (Campbell et al., 2011). Another promising strategy consists of combining the antiangiogenic property of 3TSR with the pro-apoptotic TRAIL in order to target both tumor and tumorassociated vessels (Ren et al., 2009). Such 3TSR/TRAIL fusion protein was recently demonstrated to improve survival of mice bearing intracranial human glioblastoma xenografts, therefore, suggesting a potent translational potential of 3TSR/TRAIL therapies into clinics (Choi et al., 2015).

Finally, TSP-1 peptidomimetics may be considered not only for their direct therapeutic use, but also to enhance the therapeutic delivery of cytotoxic drugs. Notably, a D-reverse peptide derived from the native KRFKQDGGWSHWSPWSSC motif within the TSR of TSP-1 was first demonstrated to inhibit breast tumor growth in a mouse xenograft model (Guo et al., 1997). More recently, an aspartimide analog based on the same TSP-1 sequence was shown to potentiate the activity of doxorubicin in colon carcinoma xenografts. Indeed, such a peptide is able to support the adhesion of doxorubicincontaining liposomes to both tumor cells and endothelial cells, thus leading to increased antiproliferative and antiangiogenic activities (Rivera-Fillat et al., 2010).

\section{CONCLUSION}

To date, mAbs targeting CD47 are the best advance toward clinical development and much interest is accorded to massive anti-CD47 blocking strategies, even within non-scientific skilled communities. Accordingly, a growing number of almost sensational reports excessively praise the therapeutic potential of CD47-targeting anticancer immunotherapies on social networks, video sharing platforms or popular-science writings (Williams, 2012; Foley, 2013), probably with a promotional and fund raising purpose. Noteworthy work of Weissman and collaborators in immunodeficient mice has proved preclinical efficacy of anti-CD47 mAbs in a wide range of xenograft models including leukemia (Chao et al., 2011a), lymphoma (Chao et al., 2011b), multiple myeloma (Kim et al., 2012), and several solid tumors (Edris et al., 2012; Willingham et al., 2012a). However, we are deeply convinced that genetic ablation or antibody blockade of CD47 may not represent a fully satisfying anticancer therapeutic alternative due to adverse effects and/or concomitant attenuation of beneficial functions, and that a more nuanced picture could be exposed to cancer patients. Indeed, massive extinction of any protein/receptor/signaling pathway might lead to adverse effects and resistance, while more accurate strategies are needed to regain the baseline. In particular, a global vision of the numerous molecular and cellular actors involved should be adopted when considering matricellular proteins and their receptors in anticancer drug development. Anti-CD47 mAbs could offer clear benefits in the treatment of cardiovascular diseases, however their use as anticancer drugs is likely to encounter the same limitations as bevacizumab, i.e., hypertension, thromboembolism, and tumor recurrence (Gil-Gil et al., 2013). While genetic modulation of CD47 expression could represent an alternative to antibody-based strategies, further clinical development of previously described morpholino-based approaches may require repeated administrations of high doses, due to morpholino oligonucleotides poor cell and tissue uptake as well as their rapid renal clearance (Moulton and Moulton, 2010). Besides, siRNA and miRNA-based strategies may provide viable alternative to morpholino-based CD47 silencing (Wang et al., 2015).

In our opinion, future research should focus on small molecules that allow a finer and more accurate regulation, thus leading to adequate responses and limited adverse effects. Among the variety of innovative approaches, peptides represent a 
fast-growing class of new therapeutics (Diao and Meibohm, 2013) and many structural modification strategies have been developed recently to improve their performance as drugs (Di, 2015). The combination of such cutting-edge strategies with conventional anticancer agents will help optimize dosing schedules, whose influence on resistance acquisition is often under evaluated, particularly among anti-VEGF approaches (Clarke and Hurwitz, 2013). Looking ahead, original and selective TSP-1-related antireceptor strategies could improve long-term benefits by overcoming many undesired effects. The next challenges will concern the translation of these small molecules into the clinic, as well as the identification of optimal combinatorial strategies with standard chemotherapy and radiotherapy.

\section{REFERENCES}

Baker, L. H., Rowinsky, E. K., Mendelson, D., Humerickhouse, R. A., Knight, R. A., Qian, J., et al. (2008). Randomized, phase II study of the thrombospondin1-mimetic angiogenesis inhibitor ABT-510 in patients with advanced soft tissue sarcoma. J. Clin. Oncol. 26, 5583-5588. doi: 10.1200/JCO.2008.1 7.4706

Barazi, H. O., Li, Z., Cashel, J. A., Krutzsch, H. C., Annis, D. S., Mosher, D. F., et al. (2002). Regulation of integrin function by CD47 ligands. Differential effects on alpha vbeta 3 and alpha 4 betal integrin-mediated adhesion. J. Biol. Chem. 277, 42859-42866. doi: 10.1074/jbc.M206849200

Bauer, P. M., Bauer, E. M., Rogers, N. M., Yao, M., Feijoo-Cuaresma, M., Pilewski, J. M., et al. (2012). Activated CD47 promotes pulmonary arterial hypertension through targeting caveolin-1. Cardiovasc. Res. 93, 682-693. doi: $10.1093 / \mathrm{cvr} / \mathrm{cvr} 356$

Baumgartner, J. M., Palmer, B. E., Banerjee, A., and McCarter, M. D. (2008). Role of melanoma secreted thrombospondin-1 on induction of immunosuppressive regulatory T cells through CD47. J. Cancer Mol. 4, 145-152.

Belotti, D., Foglieni, C., Resovi, A., Giavazzi, R., and Taraboletti, G. (2011). Targeting angiogenesis with compounds from the extracellular matrix. Int. J. Biochem. Cell Biol. 43, 1674-1685. doi: 10.1016/j.biocel.2011.08.012

Bertin, N., Clezardin, P., Kubiak, R., and Frappart, L. (1997). Thrombospondin-1 and -2 messenger RNA expression in normal, benign, and neoplastic human breast tissues: correlation with prognostic factors, tumor angiogenesis, and fibroblastic desmoplasia. Cancer Res. 57, 396-399.

Bi, J., Bai, Z., Ma, X., Song, J., Guo, Y., Zhao, J., et al. (2014). Txr1: an important factor in oxaliplatin resistance in gastric cancer. Med. Oncol. 31:807. doi: 10.1007/s12032-013-0807-1

Borsotti, P., Ghilardi, C., Ostano, P., Silini, A., Dossi, R., Pinessi, D., et al. (2015). Thrombospondin-1 is part of a Slug-independent motility and metastatic program in cutaneous melanoma, in association with VEGFR-1 and FGF-2. Pigment Cell Melanoma Res. 28, 73-81. doi: 10.1111/pcmr.12319

Bouguermouh, S., Van, V. Q., Martel, J., Gautier, P., Rubio, M., and Sarfati, M. (2008). CD47 expression on $\mathrm{T}$ cell is a self-control negative regulator of type 1 immune response. J. Immunol. 180, 8073-8082. doi: 10.4049/jimmunol.180.12.8073

Brown, E., Hooper, L., Ho, T., and Gresham, H. (1990). Integrin-associated protein: a $50-\mathrm{kD}$ plasma membrane antigen physically and functionally associated with integrins. J. Cell Biol. 111, 2785-2794. doi: 10.1083/jcb.111.6.2785

Brown, L. F., Guidi, A. J., Schnitt, S. J., Van De Water, L., Iruela-Arispe, M. L., Yeo, T. K., et al. (1999). Vascular stroma formation in carcinoma in situ, invasive carcinoma, and metastatic carcinoma of the breast. Clin. Cancer Res. 5, 1041-1056.

Byrne, G. J., Hayden, K. E., McDowell, G., Lang, H., Kirwan, C. C., Tetlow, L., et al. (2007). Angiogenic characteristics of circulating and tumoural thrombospondin-1 in breast cancer. Int. J. Oncol. 31, 1127-1132.

Calvo, D., Dopazo, J., and Vega, M. A. (1995). The CD36, CLA-1 (CD36L1), and LIMPII (CD36L2) gene family: cellular distribution, chromosomal location, and genetic evolution. Genomics 25, 100-106.

\section{AUTHOR CONTRIBUTION}

CS and LM contributed to write the manuscript; AJ and SD wrote the manuscript; SD supervised the work.

\section{ACKNOWLEDGMENTS}

The authors acknowledge supports from Centre National de la Recherche Scientifique (CNRS), Région Champagne-Ardenne and SATT Nord. AJ was recipient of grants from the Ministère de l'Enseignement Supérieur et de la Recherche (2010-13). The authors acknowledge A. Thomachot and D. Blackwell for editorial assistance.

Campbell, I. G., Freemont, P. S., Foulkes, W., and Trowsdale, J. (1992). An ovarian tumor marker with homology to vaccinia virus contains an IgV-like region and multiple transmembrane domains. Cancer Res. 52, 5416-5420.

Campbell, N., Greenaway, J., Henkin, J., and Petrik, J. (2011). ABT-898 induces tumor regression and prolongs survival in a mouse model of epithelial ovarian cancer. Mol. Cancer Ther. 10, 1876-1885. doi: 10.1158/1535-7163.MCT-110402

Catena, R., Bhattacharya, N., El Rayes, T., Wang, S., Choi, H., Gao, D., et al. (2013). Bone marrow-derived Grl+ cells can generate a metastasis-resistant microenvironment via induced secretion of thrombospondin-1. Cancer Discov. 3, 578-589. doi: 10.1158/2159-8290.CD-12-0476

Chan, K. S., Espinosa, I., Chao, M., Wong, D., Ailles, L., Diehn, M., et al. (2009). Identification, molecular characterization, clinical prognosis, and therapeutic targeting of human bladder tumor-initiating cells. Proc. Natl. Acad. Sci. U.S.A. 106, 14016-14021. doi: 10.1073/pnas.0906549106

Chao, M. P., Alizadeh, A. A., Tang, C., Jan, M., Weissman-Tsukamoto, R., Zhao, F., et al. (2011a). Therapeutic antibody targeting of CD47 eliminates human acute lymphoblastic leukemia. Cancer Res. 71, 1374-1384. doi: 10.1158/00085472.CAN-10-2238

Chao, M. P., Tang, C., Pachynski, R. K., Chin, R., Majeti, R., and Weissman, I. L. (2011b). Extranodal dissemination of non-Hodgkin lymphoma requires CD47 and is inhibited by anti-CD47 antibody therapy. Blood 118, 4890-4901. doi: 10.1182/blood-2011-02-338020

Chao, M. P., Alizadeh, A. A., Tang, C., Myklebust, J. H., Varghese, B., Gill, S., et al. (2010). Anti-CD47 antibody synergizes with rituximab to promote phagocytosis and eradicate non-Hodgkin lymphoma. Cell 142, 699-713. doi: 10.1016/j.cell.2010.07.044

Chao, M. P., Weissman, I. L., and Majeti, R. (2012). The CD47-SIRPalpha pathway in cancer immune evasion and potential therapeutic implications. Curr. Opin. Immunol. 24, 225-232. doi: 10.1016/j.coi.2012.01.010

Choi, S. H., Tamura, K., Khajuria, R. K., Bhere, D., Nesterenko, I., Lawler, J., et al. (2015). Antiangiogenic variant of TSP-1 targets tumor cells in glioblastomas. Mol. Ther. 23, 235-243. doi: 10.1038/mt.2014.214

Clarke, J. M., and Hurwitz, H. I. (2013). Understanding and targeting resistance to anti-angiogenic therapies. J. Gastrointest. Oncol. 4, 253-263. doi: 10.3978/j.issn.2078-6891.2013.036

Clemetson, K. J., Pfueller, S. L., Luscher, E. F., and Jenkins, C. S. (1977). Isolation of the membrane glycoproteins of human blood platelets by lectin affinity chromatography. Biochim. Biophys. Acta 464, 493-508. doi: 10.1016/00052736(77)90025-6

Clezardin, P., Frappart, L., Clerget, M., Pechoux, C., and Delmas, P. D. (1993). Expression of thrombospondin (TSP1) and its receptors (CD36 and CD51) in normal, hyperplastic, and neoplastic human breast. Cancer Res. 53, 1421-1430.

Colombo, G., Margosio, B., Ragona, L., Neves, M., Bonifacio, S., Annis, D. S., et al. (2010). Non-peptidic thrombospondin-1 mimics as fibroblast growth factor-2 inhibitors: an integrated strategy for the development of new antiangiogenic compounds. J. Biol. Chem. 285, 8733-8742. doi: 10.1074/jbc.M109.0 85605 
Coronella, J., Li, L., Johnson, K., Pirie-Shepherd, S., Roxas, G., and Levin, N. (2009). Selective activity against proliferating tumor endothelial cells by CVX-22, a thrombospondin-1 mimetic CovX-Body. Anticancer Res. 29, 2243-2252.

Dameron, K. M., Volpert, O. V., Tainsky, M. A., and Bouck, N. (1994). Control of angiogenesis in fibroblasts by 533 regulation of thrombospondin-1. Science 265 , 1582-1584. doi: 10.1126/science.7521539

Dawes, J., Pratt, D. A., Dewar, M. S., and Preston, F. E. (1988). Do extra-platelet sources contribute to the plasma level of thrombospondin? Thromb. Haemost. 59, 273-276.

Dawson, D. W., Pearce, S. F., Zhong, R., Silverstein, R. L., Frazier, W. A., and Bouck, N. P. (1997). CD36 mediates the In vitro inhibitory effects of thrombospondin-1 on endothelial cells. J. Cell Biol. 138, 707-717. doi: 10.1083/jcb.138.3.707

Demaria, S., and Formenti, S. C. (2012). Role of T lymphocytes in tumor response to radiotherapy. Front. Oncol. 2:95. doi: 10.3389/fonc.2012.00095

Di, L. (2015). Strategic approaches to optimizing peptide ADME properties. AAPS J. 17, 134-143.

Diao, L., and Meibohm, B. (2013). Pharmacokinetics and pharmacokineticpharmacodynamic correlations of therapeutic peptides. Clin. Pharmacokinet. 52, 855-868. doi: 10.1007/s40262-013-0079-0

Dossi, R., Frapolli, R., Di Giandomenico, S., Paracchini, L., Bozzi, F., Brich, S., et al. (2015). Antiangiogenic activity of trabectedin in myxoid liposarcoma: involvement of host TIMP-1 and TIMP-2 and tumor thrombospondin-1. Int. J. Cancer 136, 721-729. doi: 10.1002/ijc.29023

Ebbinghaus, S., Hussain, M., Tannir, N., Gordon, M., Desai, A. A., Knight, R. A., et al. (2007). Phase 2 study of ABT-510 in patients with previously untreated advanced renal cell carcinoma. Clin. Cancer Res. 13, 6689-6695. doi: 10.1158/1078-0432.CCR-07-1477

Edris, B., Weiskopf, K., Volkmer, A. K., Volkmer, J.-P., Willingham, S. B., Contreras-Trujillo, H., et al. (2012). Antibody therapy targeting the CD47 protein is effective in a model of aggressive metastatic leiomyosarcoma. Proc. Natl. Acad. Sci. U.S.A. 109, 6656-6661. doi: 10.1073/pnas.1121629109

Floquet, N., Dedieu, S., Martiny, L., Dauchez, M., and Perahia, D. (2008). Human thrombospondin's (TSP-1) C-terminal domain opens to interact with the CD47 receptor: a molecular modeling study. Arch. Biochem. Biophys. 478, 103-109. doi: 10.1016/j.abb.2008.07.015

Foley, J. (2013). Ultimate Antibody Cures Every Type Of Cancer In Clinical Tests. Nature World News. Available at: http://www.natureworldnews.com/ articles/1091/20130329/ultimate-antibody-cures-type-cancer-clinical-testsvideo.htm.

Fujimoto, T.-T., Katsutani, S., Shimomura, T., and Fujimura, K. (2003). Thrombospondin-bound integrin-associated protein (CD47) physically and functionally modifies integrin alphaIIbbeta3 by its extracellular domain. J. Biol. Chem. 278, 26655-26665. doi: 10.1074/jbc.M302194200

Gao, A. G., and Frazier, W. A. (1994). Identification of a receptor candidate for the carboxyl-terminal cell binding domain of thrombospondins. J. Biol. Chem. 269, 29650-29657.

Gietema, J. A., Hoekstra, R., de Vos, F. Y., Uges, D. R., van der Gaast, A., Groen, H. J. M., et al. (2006). A phase I study assessing the safety and pharmacokinetics of the thrombospondin-1-mimetic angiogenesis inhibitor ABT-510 with gemcitabine and cisplatin in patients with solid tumors. Ann. Oncol. 17, 1320-1327. doi: 10.1093/annonc/mdl102

Gil-Gil, M. J., Mesia, C., Rey, M., and Bruna, J. (2013). Bevacizumab for the treatment of glioblastoma. Clin. Med. Insights Oncol. 7, 123-135. doi: 10.4137/CMO.S8503

Grimbert, P., Bouguermouh, S., Baba, N., Nakajima, T., Allakhverdi, Z., Braun, D., et al. (2006). Thrombospondin/CD47 interaction: a pathway to generate regulatory $\mathrm{T}$ cells from human $\mathrm{CD} 4+\mathrm{CD} 25-\mathrm{T}$ cells in response to inflammation. J. Immunol. 177, 3534-3541. doi: 10.4049/jimmunol.177.6.3534

Guo, N. H., Krutzsch, H. C., Inman, J. K., Shannon, C. S., and Roberts, D. D. (1997). Antiproliferative and antitumor activities of D-reverse peptides derived from the second type-1 repeat of thrombospondin-1. J. Pept. Res. 50, 210-221. doi: 10.1111/j.1399-3011.1997.tb01187.x

Han, X., Sterling, H., Chen, Y., Saginario, C., Brown, E. J., Frazier, W. A., et al. (2000). CD47, a ligand for the macrophage fusion receptor, participates in macrophage multinucleation. J. Biol. Chem. 275, 37984-37992. doi: 10.1074/jbc.M002334200

Hatherley, D., Graham, S. C., Turner, J., Harlos, K., Stuart, D. I., and Barclay, A. N. (2008). Paired receptor specificity explained by structures of signal regulatory proteins alone and complexed with CD47. Mol. Cell 31, 266-277. doi: 10.1016/j.molcel.2008.05.026

Haviv, F., Bradley, M. F., Kalvin, D. M., Schneider, A. J., Davidson, D. J., Majest, S. M., et al. (2005). Thrombospondin-1 mimetic peptide inhibitors of angiogenesis and tumor growth: design, synthesis, and optimization of pharmacokinetics and biological activities. J. Med. Chem. 48, 2838-2846. doi: $10.1021 / j m 0401560$

Henkin, J., and Volpert, O. V. (2011). Therapies using anti-angiogenic peptide mimetics of thrombospondin-1. Expert Opin. Ther. Targets 15, 1369-1386. doi: $10.1517 / 14728222.2011 .640319$

Hirano, K., Kuwasako, T., Nakagawa-Toyama, Y., Janabi, M., Yamashita, S., and Matsuzawa, Y. (2003). Pathophysiology of human genetic CD36 deficiency. Trends Cardiovasc. Med. 13, 136-141. doi: 10.1016/S1050-1738(03)0 0026-4

Ho, C. C. M., Guo, N., Sockolosky, J. T., Ring, A. M., Weiskopf, K., Özkan, E., et al. (2015). "Velcro" engineering of high affinity CD47 ectodomain as signal regulatory protein $\alpha(\operatorname{SIRP} \alpha)$ antagonists that enhance antibodydependent cellular phagocytosis. J. Biol. Chem. 290, 12650-12663. doi: 10.1074/jbc.M115.648220

Hoekstra, R., de Vos, F. Y., Eskens, F. A., Gietema, J. A., van der Gaast, A., Groen, H. J. M., et al. (2005). Phase I safety, pharmacokinetic, and pharmacodynamic study of the thrombospondin-1-mimetic angiogenesis inhibitor ABT-510 in patients with advanced cancer. J. Clin. Oncol. 23, 5188-5197. doi: 10.1200/JCO.2005.05.013

Incardona, F., Lewalle, J. M., Morandi, V., Lambert, S., Legrand, Y., Foidart, J. M., et al. (1995). Thrombospondin modulates human breast adenocarcinoma cell adhesion to human vascular endothelial cells. Cancer Res. 55, $166-173$.

Isenberg, J. S., Annis, D. S., Pendrak, M. L., Ptaszynska, M., Frazier, W. A., Mosher, D. F., et al. (2009a). Differential interactions of thrombospondin-1, -2 , and -4 with CD47 and effects on cGMP signaling and ischemic injury responses. J. Biol. Chem. 284, 1116-1125. doi: 10.1074/jbc.M804860200

Isenberg, J. S., Martin-Manso, G., Maxhimer, J. B., and Roberts, D. D. (2009b). Regulation of nitric oxide signalling by thrombospondin 1: implications for anti-angiogenic therapies. Nat. Rev. Cancer 9, 182-194. doi: 10.1038/n rc2561

Isenberg, J. S., Shiva, S., and Gladwin, M. (2009c). Thrombospondin-1-CD47 blockade and exogenous nitrite enhance ischemic tissue survival, blood flow and angiogenesis via coupled NO-cGMP pathway activation. Nitric Oxide 21, 52-62. doi: 10.1016/j.niox.2009.05.005

Isenberg, J. S., Frazier, W. A., and Roberts, D. D. (2008a). Thrombospondin-1: a physiological regulator of nitric oxide signaling. Cell. Mol. Life Sci. 65, 728-742. doi: 10.1007/s00018-007-7488-x

Isenberg, J. S., Hyodo, F., Ridnour, L. A., Shannon, C. S., Wink, D. A., Krishna, M. C., et al. (2008b). Thrombospondin 1 and vasoactive agents indirectly alter tumor blood flow. Neoplasia 10, 886-896. doi: 10.1593/neo.08264

Isenberg, J. S., Maxhimer, J. B., Hyodo, F., Pendrak, M. L., Ridnour, L. A., DeGraff, W. G., et al. (2008c). Thrombospondin-1 and CD47 limit cell and tissue survival of radiation injury. Am. J. Pathol. 173, 1100-1112. doi: 10.2353/ajpath.2008.080237

Isenberg, J. S., Romeo, M. J., Yu, C., Yu, C. K., Nghiem, K., Monsale, J., et al. (2008d). Thrombospondin-1 stimulates platelet aggregation by blocking the antithrombotic activity of nitric oxide/cGMP signaling. Blood 111, 613-623. doi: 10.1182/blood-2007-06-098392

Isenberg, J. S., Jia, Y., Fukuyama, J., Switzer, C. H., Wink, D. A., and Roberts, D. D. (2007). Thrombospondin-1 inhibits nitric oxide signaling via CD36 by inhibiting myristic acid uptake. J. Biol. Chem. 282, 15404-15415. doi: 10.1074/jbc.M701638200

Isenberg, J. S., Ridnour, L. A., Dimitry, J., Frazier, W. A., Wink, D. A., and Roberts, D. D. (2006). CD47 is necessary for inhibition of nitric oxide-stimulated vascular cell responses by thrombospondin-1. J. Biol. Chem. 281, 26069-26080. doi: 10.1074/jbc.M605040200

Jaiswal, S., Jamieson, C. H. M., Pang, W. W., Park, C. Y., Chao, M. P., Majeti, R., et al. (2009). CD47 is upregulated on circulating hematopoietic stem cells and leukemia cells to avoid phagocytosis. Cell 138, 271-285. doi: 10.1016/j.cell.2009.05.046

Jayachandran, A., Anaka, M., Prithviraj, P., Hudson, C., McKeown, S. J., Lo, P.-H., et al. (2014). Thrombospondin 1 promotes an aggressive phenotype 
through epithelial-to-mesenchymal transition in human melanoma. Oncotarget 5, 5782-5797. doi: 10.18632/oncotarget.2164

Jeanne, A., Sick, E., Devy, J., Floquet, N., Belloy, N., Theret, L., et al. (2015). Identification of TAX2 Peptide as a New Unpredicted Anti-Cancer Agent. Oncotarget 5. Available at: http://www.impactjournals.com/oncotarget/in dex.php?journal $=$ oncotarget\&page $=$ article\&op $=$ view\&path $\% 5 B \% 5 \mathrm{D}=4025$ [accessed July 6, 2015].

Kalas, W., Swiderek, E., Świtalska, M., Wietrzyk, J., Rak, J., and Strzçdała, L. (2013). Thrombospondin-1 receptor mediates autophagy of RAS-expressing cancer cells and triggers tumour growth inhibition. Anticancer. Res. 33, 1429-1438.

Kaur, S., Chang, T., Singh, S. P., Lim, L., Mannan, P., Garfield, S. H., et al. (2014), CD47 signaling regulates the immunosuppressive activity of VEGF in T cells. J. Immunol. 193, 3914-3924. doi: 10.4049/jimmunol.1303116

Kaur, S., Martin-Manso, G., Pendrak, M. L., Garfield, S. H., Isenberg, J. S., and Roberts, D. D. (2010). Thrombospondin-1 inhibits VEGF receptor-2 signaling by disrupting its association with CD47. J. Biol. Chem. 285, 38923-38932. doi: 10.1074/jbc.M110.172304

Kaur, S., Schwartz, A. L., Miller, T. W., and Roberts, D. D. (2015). CD47-dependent regulation of $\mathrm{H} 2 \mathrm{~S}$ biosynthesis and signaling in T cells. Methods Enzymol. 555, 145-168. doi: 10.1016/bs.mie.2014.11.023

Kazerounian, S., Yee, K. O., and Lawler, J. (2008). Thrombospondins in cancer. Cell. Mol. Life Sci. 65, 700-712. doi: 10.1007/s00018-007-7486-Z

Kim, D., Wang, J., Willingham, S. B., Martin, R., Wernig, G., and Weissman, I. L. (2012). Anti-CD47 antibodies promote phagocytosis and inhibit the growth of human myeloma cells. Leukemia 26, 2538-2545. doi: 10.1038/leu.201 2.141

Kim, M. J., Lee, J.-C., Lee, J.-J., Kim, S., Lee, S. G., Park, S.-W., et al. (2008). Association of CD47 with natural killer cell-mediated cytotoxicity of headand-neck squamous cell carcinoma lines. Tumour Biol. 29, 28-34. doi: $10.1159 / 000132568$

Koonen, D. P., Glatz, J. F. C., Bonen, A., and Luiken, J. J. F. P. (2005), Long-chain fatty acid uptake and FAT/CD36 translocation in heart and skeletal muscle. Biochim. Biophys. Acta 1736, 163-180. doi: 10.1016/j.bbalip.200 5.08 .018

Kvansakul, M., Adams, J. C., and Hohenester, E. (2004). Structure of a thrombospondin C-terminal fragment reveals a novel calcium core in the type 3 repeats. $E M B O$ J. 23, 1223-1233. doi: 10.1038/sj.emboj.7600166

Latour, S., Tanaka, H., Demeure, C., Mateo, V., Rubio, M., Brown, E. J., et al. (2001). Bidirectional negative regulation of human $\mathrm{T}$ and dendritic cells by $\mathrm{CD} 47$ and its cognate receptor signal-regulator protein- $\alpha$ : down-Regulation of IL-12 responsiveness and inhibition of dendritic cell activation. J. Immunol. 167, 2547-2554. doi: 10.4049/jimmunol.167.5.2547

Lawler, J. W., Slayter, H. S., and Coligan, J. E. (1978). Isolation and characterization of a high molecular weight glycoprotein from human blood platelets. J. Biol. Chem. 253, 8609-8616.

Leclair, P., and Lim, C. J. (2014). CD47-independent effects mediated by the TSP-derived 4N1K peptide. PLoS ONE 9:e98358. doi: 10.1371/journal.pone.00 98358

Lee, T. K.-W., Cheung, V. C.-H., Lu, P., Lau, E. Y. T., Ma, S., Tang, K. H., et al. (2014). Blockade of CD47-mediated cathepsin S/protease-activated receptor 2 signaling provides a therapeutic target for hepatocellular carcinoma. Hepatology 60, 179-191. doi: 10.1002/hep.27070

Lee, Y.-J., Koch, M., Karl, D., Torres-Collado, A. X., Fernando, N. T., Rothrock, C., et al. (2010). Variable inhibition of thrombospondin 1 against liver and lung metastases through differential activation of metalloproteinase ADAMTS1. Cancer Res. 70, 948-956. doi: 10.1158/0008-5472.CAN-09-3094

Levin, N. J., Leedom, T. A., Doppalapudi, V. R., Li, L., Lai, J., Johnson, K., et al. (2007). CVX-045: a novel thrombospondin-1 (TSP-1) mimetic CovX-Body that potentiates chemotherapy in preclinical colon cancer models. J. Clin. Oncol. 25, 14011.

Li, L., Leedom, T. A., Do, J., Huang, H., Lai, J., Johnson, K., et al. (2011). Antitumor efficacy of a thrombospondin 1 mimetic CovX-body. Transl. Oncol. 4, 249-257. doi: 10.1593/tlo.11136

Li, S. S., Liu, Z., Uzunel, M., and Sundqvist, K.-G. (2006). Endogenous thrombospondin-1 is a cell-surface ligand for regulation of integrin-dependent T-lymphocyte adhesion. Blood 108, 3112-3120. doi: 10.1182/blood-2006-04016832
Li, Z., Calzada, M. J., Sipes, J. M., Cashel, J. A., Krutzsch, H. C., Annis, D. S., et al. (2002). Interactions of thrombospondins with alpha4betal integrin and CD47 differentially modulate T cell behavior. J. Cell Biol. 157, 509-519. doi: $10.1083 /$ jcb. 200109098

Li, Z., He, L., Wilson, K., and Roberts, D. (2001). Thrombospondin-1 inhibits TCR-mediated T lymphocyte early activation. J. Immunol. 166, 2427-2436. doi: 10.4049/jimmunol.166.4.2427

Lih, C.-J., Wei, W., and Cohen, S. N. (2006). Txr1: a transcriptional regulator of thrombospondin-1 that modulates cellular sensitivity to taxanes. Genes Dev. 20, 2082-2095. doi: 10.1101/gad.1441306

Lin, X.-D., Chen, S.-Q., Qi, Y.-L., Zhu, J.-W., Tang, Y., and Lin, J.-Y. (2012). Overexpression of thrombospondin-1 in stromal myofibroblasts is associated with tumor growth and nodal metastasis in gastric carcinoma. J. Surg. Oncol. 106, 94-100. doi: 10.1002/jso.23037

Lin, Y., Manning, P. T., Jia, J., Gaut, J. P., Xiao, Z., Capoccia, B. J., et al. (2014). CD47 blockade reduces ischemia-reperfusion injury and improves outcomes in a rat kidney transplant model. Transplantation 98, 394-401. doi: 10.1097/TP.0000000000000252

Lutz, H. U., and Bogdanova, A. (2013). Mechanisms tagging senescent red blood cells for clearance in healthy humans. Front. Physiol. 4:387. doi: 10.3389/fphys.2013.00387

Lyu, T., Jia, N., Wang, J., Yan, X., Yu, Y., Lu, Z., et al. (2013). Expression and epigenetic regulation of angiogenesis-related factors during dormancy and recurrent growth of ovarian carcinoma. Epigenetics 8, 1330-1346. doi: 10.4161/epi.26675

Maile, L. A., Capps, B. E., Miller, E. C., Aday, A. W., and Clemmons, D. R. (2008). Integrin-associated protein association with Src homology 2 domain containing tyrosine phosphatase substrate 1 regulates IGF-I signaling in vivo. Diabetes 57, 2637-2643. doi: 10.2337/db08-0326

Majeti, R., Chao, M. P., Alizadeh, A. A., Pang, W. W., Jaiswal, S., Gibbs, K. D., et al. (2009). CD47 is an adverse prognostic factor and therapeutic antibody target on human acute myeloid leukemia stem cells. Cell 138, 286-299. doi: 10.1016/j.cell.2009.05.045

Manna, P. P., and Frazier, W. A. (2004). CD47 mediates killing of breast tumor cells via Gi-dependent inhibition of protein kinase A. Cancer Res. 64, 1026-1036. doi: 10.1158/0008-5472.CAN-03-1708

Markovic, S. N., Suman, V. J., Rao, R. A., Ingle, J. N., Kaur, J. S., Erickson, L. A., et al. (2007). A phase II study of ABT-510 (thrombospondin-1 analog) for the treatment of metastatic melanoma. Am. J. Clin. Oncol. 30, 303-309. doi: 10.1097/01.coc.0000256104.80089.35

Martin, D. D. O., Beauchamp, E., and Berthiaume, L. G. (2011). Post-translational myristoylation: fat matters in cellular life and death. Biochimie 93, 18-31. doi: 10.1016/j.biochi.2010.10.018

Martinez-Torres, A.-C., Quiney, C., Attout, T., Boullet, H., Herbi, L., Vela, L., et al. (2015). CD47 agonist peptides induce programmed cell death in refractory chronic lymphocytic leukemia B cells via PLC $\gamma 1$ activation: evidence from mice and humans. PLoS Med. 12:e1001796. doi: 10.1371/journal.pmed.10 01796

Mawby, W. J., Holmes, C. H., Anstee, D. J., Spring, F. A., and Tanner, M. J. (1994). Isolation and characterization of CD47 glycoprotein: a multispanning membrane protein which is the same as integrin-associated protein (IAP) and the ovarian tumour marker OA3. Biochem. J. 304(Pt 2), 525-530. doi: 10.1042/bj3040525

Maxhimer, J. B., Soto-Pantoja, D. R., Ridnour, L. A., Shih, H. B., Degraff, W. G., Tsokos, M., et al. (2009). Radioprotection in normal tissue and delayed tumor growth by blockade of CD47 signaling. Sci. Transl. Med. 1:3ra7. doi: 10.1126/scitranslmed.3000139

McCracken, M. N., Cha, A. C., and Weissman, I. L. (2015). Molecular pathways: activating $t$ cells after cancer cell phagocytosis from blockade of CD47 "Don't Eat Me" signals. Clin. Cancer Res. 21, 3597-3601. doi: 10.1158/1078-0432.CCR14-2520

McDonald, J. F., Zheleznyak, A., and Frazier, W. A. (2004). Cholesterol-independent interactions with CD47 enhance alphavbeta3 avidity. J. Biol. Chem. 279, 17301-17311. doi: 10.1074/jbc.M3127 82200

Meli, M., Pagano, K., Ragona, L., and Colombo, G. (2014). Investigating the dynamic aspects of drug-protein recognition through a combination of MD and NMR analyses: implications for the development of protein-protein 
interaction inhibitors. PLOS ONE 9:e97153. doi: 10.1371/journal.pone.00 97153

Miao, W. M., Seng, W. L., Duquette, M., Lawler, P., Laus, C., and Lawler, J. (2001). Thrombospondin-1 type 1 repeat recombinant proteins inhibit tumor growth through transforming growth factor-beta-dependent and -independent mechanisms. Cancer Res. 61, 7830-7839.

Mohandas, N., and Gallagher, P. G. (2008). Red cell membrane: past, present, and future. Blood 112, 3939-3948. doi: 10.1182/blood-2008-07-161166

Molckovsky, A., and Siu, L. L. (2008). First-in-class, first-in-human phase I results of targeted agents: highlights of the 2008 American Society of Clinical Oncology meeting. J. Hematol. Oncol. 1:20.

Monk, B. J., Dalton, H., Benjamin, I., and Tanović, A. (2012). Trabectedin as a new chemotherapy option in the treatment of relapsed platinum sensitive ovarian cancer. Curr. Pharm. Des. 18, 3754-3769. doi: 10.2174/1381612128020 02814

Moulton, H. M., and Moulton, J. D. (2010). Morpholinos and their peptide conjugates: rherapeutic promise and challenge for Duchenne muscular dystrophy. Biochim. Biophys. Acta 1798, 2296-2303. doi: 10.1016/j.bbamem.2010.02.012

Murphy-Ullrich, J. E., and Sage, E. H. (2014). Revisiting the matricellular concept. Matrix Biol. 37, 1-14. doi: 10.1016/j.matbio.2014.07.005

Nathan, F. E., Hernandez, E., Dunton, C. J., Treat, J., Switalska, H. I., Joseph, R. R., et al. (1994). Plasma thrombospondin levels in patients with gynecologic malignancies. Cancer 73, 2853-2858.

Naumov, G. N., Bender, E., Zurakowski, D., Kang, S.-Y., Sampson, D., Flynn, E., et al. (2006). A model of human tumor dormancy: an angiogenic switch from the nonangiogenic phenotype. J. Natl. Cancer Inst. 98, 316-325. doi: 10.1093/jnci/djj068

Nie, S., Lo, A., Wu, J., Zhu, J., Tan, Z., Simeone, D. M., et al. (2014). Glycoprotein biomarker panel for pancreatic cancer discovered by quantitative proteomics analysis. J. Proteome Res. 13, 1873-1884. doi: 10.1021/pr40 0967x

Novelli, E. M., Kato, G. J., Ragni, M. V., Zhang, Y., Hildesheim, M. E., Nouraie, M., et al. (2012). Plasma thrombospondin-1 is increased during acute sickle cell vaso-occlusive events and associated with acute chest syndrome, hydroxyurea therapy, and lower hemolytic rates. Am. J. Hematol. 87, 326-330. doi: 10.1002/ajh.22274

Ohnishi, H., Kobayashi, H., Okazawa, H., Ohe, Y., Tomizawa, K., Sato, R., et al. (2004). Ectodomain shedding of SHPS-1 and its role in regulation of cell migration. J. Biol. Chem. 279, 27878-27887. doi: 10.1074/jbc.M313085200

Oldenborg, P. A., Zheleznyak, A., Fang, Y. F., Lagenaur, C. F., Gresham, H. D., and Lindberg, F. P. (2000). Role of CD47 as a marker of self on red blood cells. Science 288, 2051-2054. doi: 10.1126/science.288.5473.2051

Olsson, M., Bruhns, P., Frazier, W. A., Ravetch, J. V., and Oldenborg, P.-A. (2005). Platelet homeostasis is regulated by platelet expression of CD47 under normal conditions and in passive immune thrombocytopenia. Blood 105, 3577-3582. doi: 10.1182/blood-2004-08-2980

Pagano, K., Torella, R., Foglieni, C., Bugatti, A., Tomaselli, S., Zetta, L., et al. (2012). Direct and allosteric inhibition of the FGF2/HSPGs/FGFR1 ternary complex formation by an antiangiogenic, thrombospondin-1-mimic small molecule. PLoS ONE 7:e36990. doi: 10.1371/journal.pone.0036990

Perez-Janices, N., Blanco-Luquin, I., Tuñón, M. T., Barba-Ramos, E., Ibáñez, B., Zazpe-Cenoz, I., et al. (2015). EPB41L3, TSP-1 and RASSF2 as new clinically relevant prognostic biomarkers in diffuse gliomas. Oncotarget 6, 368-380.

Pinessi, D., Ostano, P., Borsotti, P., Bello, E., Guffanti, F., Bizzaro, F., et al. (2015). Expression of thrombospondin-1 by tumor cells in patientderived ovarian carcinoma xenografts. Connect. Tissue Res. 56, 355-363. doi: 10.3109/03008207.2015.1045065

Pohl, J., Ring, A., Korkmaz, U., Ehehalt, R., and Stremmel, W. (2005). FAT/CD36mediated long-chain fatty acid uptake in adipocytes requires plasma membrane rafts. Mol. Biol. Cell 16, 24-31. doi: 10.1091/mbc.E04-07-0616

Qian, X., and Tuszynski, G. P. (1996). Expression of thrombospondin-1 in cancer: a role in tumor progression. Proc. Soc. Exp. Biol. Med. 212, 199-207. doi: 10.3181/00379727-212-44008

Rader, C. (2014). Chemically programmed antibodies. Trends Biotechnol. 32, 186-197. doi: 10.1016/j.tibtech.2014.02.003

Ramanathan, S., Mazzalupo, S., Boitano, S., and Montfort, W. R. (2011). Thrombospondin-1 and angiotensin II inhibit soluble guanylyl cyclase through an increase in intracellular calcium concentration. Biochemistry 50, 7787-7799. doi: 10.1021/bi201060c

Rath, G. M., Schneider, C., Dedieu, S., Rothhut, B., Soula-Rothhut, M., Ghoneim, C., et al. (2006a). The C-terminal CD47/IAP-binding domain of thrombospondin-1 prevents camptothecin- and doxorubicin-induced apoptosis in human thyroid carcinoma cells. Biochim. Biophys. Acta 1763, 1125-1134. doi: 10.1016/j.bbamcr.2006.08.001

Rath, G. M., Schneider, C., Dedieu, S., Sartelet, H., Morjani, H., Martiny, L., et al. (2006b). Thrombospondin-1 C-terminal-derived peptide protects thyroid cells from ceramide-induced apoptosis through the adenylyl cyclase pathway. Int. J. Biochem. Cell Biol. 38, 2219-2228. doi: 10.1016/j.biocel.2006.07.004

Ren, B., Song, K., Parangi, S., Jin, T., Ye, M., Humphreys, R., et al. (2009). A double hit to kill tumor and endothelial cells by TRAIL and antiangiogenic 3TSR. Cancer Res. 69, 3856-3865. doi: 10.1158/0008-5472.CAN-08-2940

Ridnour, L. A., Cheng, R. Y. S., Weiss, J. M., Kaur, S., Soto-Pantoja, D. R., Basudhar, D., et al. (2015). NOS inhibition modulates immune polarization and improves radiation-induced tumor growth delay. Cancer Res. 75, 2788-2799. doi: 10.1158/0008-5472.CAN-14-3011

Riessen, R., Kearney, M., Lawler, J., and Isner, J. M. (1998). Immunolocalization of thrombospondin-1 in human atherosclerotic and restenotic arteries. Am. Heart. J. 135, 357-364. doi: 10.1016/S0002-8703(98)70105-X

Rivera-Fillat, M. P., Reig, F., Martínez, E. M., and Grau-Oliete, M. R. (2010). Improved therapeutic responses for liposomal doxorubicin targeted via thrombospondin peptidomimetics versus untargeted doxorubicin. J. Pept. Sci. 16, 315-321. doi: 10.1002/psc.1241

Roberts, D. D., Isenberg, J. S., Ridnour, L. A., and Wink, D. A. (2007). Nitric oxide and its gatekeeper thrombospondin-1 in tumor angiogenesis. Clin. Cancer Res. 13, 795-798. doi: 10.1158/1078-0432.CCR-06-1758

Rogers, N. M., Sharifi-Sanjani, M., Csányi, G., Pagano, P. J., and Isenberg, J. S. (2014). Thrombospondin-1 and CD47 regulation of cardiac, pulmonary and vascular responses in health and disease. Matrix Biol. 37, 92-101. doi: 10.1016/j.matbio.2014.01.002

Rusk, A., McKeegan, E., Haviv, F., Majest, S., Henkin, J., and Khanna, C. (2006). Preclinical evaluation of antiangiogenic thrombospondin-1 peptide mimetics, ABT-526 and ABT-510, in companion dogs with naturally occurring cancers. Clin. Cancer Res. 12, 7444-7455. doi: 10.1158/1078-0432.CCR-06-0109

Russell, S., Duquette, M., Liu, J., Drapkin, R., Lawler, J., and Petrik, J. (2015). Combined therapy with thrombospondin-1 type I repeats (3TSR) and chemotherapy induces regression and significantly improves survival in a preclinical model of advanced stage epithelial ovarian cancer. FASEB J. 29, 576-588. doi: 10.1096/fj.14-261636

Sage, E. H., and Bornstein, P. (1991). Extracellular proteins that modulate cellmatrix interactions. SPARC, tenascin, and thrombospondin. J. Biol. Chem. 266, 14831-14834.

Sahora, A. I., Rusk, A. W., Henkin, J., McKeegan, E. M., Shi, Y., and Khanna, C. (2012). Prospective study of thrombospondin-1 mimetic peptides, ABT-510 and ABT-898, in dogs with soft tissue sarcoma. J. Vet. Intern. Med. 26, 11691176. doi: 10.1111/j.1939-1676.2012.00966.x

Sarfati, M., Fortin, G., Raymond, M., and Susin, S. (2008). CD47 in the immune response: role of thrombospondin and SIRP-alpha reverse signaling. Curr. Drug Targets 9, 842-850. doi: 10.2174/138945008785 909310

Saumet, A., Slimane, M. B., Lanotte, M., Lawler, J., and Dubernard, V. (2005). Type 3 repeat/C-terminal domain of thrombospondin-1 triggers caspase-independent cell death through CD47/alphavbeta3 in promyelocytic leukemia NB4 cells. Blood 106, 658-667. doi: 10.1182/blood-20 04-09-3585

Sick, E., Boukhari, A., Deramaudt, T., Rondé, P., Bucher, B., André, P., et al. (2011). Activation of CD47 receptors causes proliferation of human astrocytoma but not normal astrocytes via an Akt-dependent pathway. Glia 59, 308-319. doi: 10.1002/glia.21102

Sick, E., Jeanne, A., Schneider, C., Dedieu, S., Takeda, K., and Martiny, L. (2012). CD47 update: a multifaceted actor in the tumour microenvironment of potential therapeutic interest. Br. J. Pharmacol. 167, 1415-1430. doi: 10.1111/j.1476-5381.2012.02099.x

Silverstein, R. L., and Febbraio, M. (2009). CD36, a scavenger receptor involved in immunity, metabolism, angiogenesis, and behavior. Sci. Signal. 2:re3. doi: $10.1126 /$ scisignal.272re3 
Soto-Pantoja, D. R., Kaur, S., and Roberts, D. D. (2015). CD47 signaling pathways controlling cellular differentiation and responses to stress. Crit. Rev. Biochem. Mol. Biol. 50, 212-230. doi: 10.3109/10409238.2015.1014024

Soto-Pantoja, D. R., Miller, T. W., Frazier, W. A., and Roberts, D. D. (2012a). Inhibitory signaling through signal regulatory protein- $\alpha$ is not sufficient to explain the antitumor activities of CD47 antibodies. Proc. Natl. Acad. Sci. U.S.A. 109, E2842-E2842. doi: 10.1073/pnas.1205441109

Soto-Pantoja, D. R., Miller, T. W., Pendrak, M. L., DeGraff, W. G., Sullivan, C., Ridnour, L. A., et al. (2012b). CD47 deficiency confers cell and tissue radioprotection by activation of autophagy. Autophagy 8, 1628-1642. doi: 10.4161 /auto. 21562

Soto-Pantoja, D. R., Ridnour, L. A., Wink, D. A., and Roberts, D. D. (2013a). Blockade of CD47 increases survival of mice exposed to lethal total body irradiation. Sci. Rep. 3:1038. doi: 10.1038/srep01038

Soto-Pantoja, D. R., Stein, E. V., Rogers, N. M., Sharifi-Sanjani, M., Isenberg, J. S., and Roberts, D. D. (2013b). Therapeutic opportunities for targeting the ubiquitous cell surface receptor CD47. Expert Opin. Ther. Targets 17, 89-103. doi: $10.1517 / 14728222.2013 .733699$

Soto-Pantoja, D. R., Terabe, M., Ghosh, A., Ridnour, L. A., DeGraff, W. G., Wink, D. A., et al. (2014). CD47 in the tumor microenvironment limits cooperation between antitumor T-cell immunity and radiotherapy. Cancer Res. 74, 67716783. doi: 10.1158/0008-5472.CAN-14-0037-T

Starlinger, P., Moll, H. P., Assinger, A., Nemeth, C., Hoetzenecker, K., Gruenberger, B., et al. (2010). Thrombospondin-1: a unique marker to identify in vitro platelet activation when monitoring in vivo processes. J. Thromb. Haemost. 8, 1809-1819. doi: 10.1111/j.1538-7836.2010.03908.x

Taraboletti, G., Rusnati, M., Ragona, L., and Colombo, G. (2010). Targeting tumor angiogenesis with TSP-1-based compounds: rational design of antiangiogenic mimetics of endogenous inhibitors. Oncotarget 1, 662-673. doi: 10.18632/oncotarget. 200

Toth, A. B., Terauchi, A., Zhang, L. Y., Johnson-Venkatesh, E. M., Larsen, D. J., Sutton, M. A., et al. (2013). Synapse maturation by activitydependent ectodomain shedding of SIRP $\alpha$. Nat. Neurosci. 16, 1417-1425. doi: 10.1038/nn.3516

Tsai, R. K., and Discher, D. E. (2008). Inhibition of "self" engulfment through deactivation of myosin-II at the phagocytic synapse between human cells. J. Cell Biol. 180, 989-1003. doi: 10.1083/jcb.200708043

Tseng, D., Volkmer, J.-P., Willingham, S. B., Contreras-Trujillo, H., Fathman, J. W., Fernhoff, N. B., et al. (2013). Anti-CD47 antibody-mediated phagocytosis of cancer by macrophages primes an effective antitumor T-cell response. Proc. Natl. Acad. Sci. U.S.A. 110, 11103-11108. doi: 10.1073/pnas. 1305 569110

Tulasne, D., Judd, B. A., Johansen, M., Asazuma, N., Best, D., Brown, E. J., et al. (2001). C-terminal peptide of thrombospondin-1 induces platelet aggregation through the $\mathrm{Fc}$ receptor gamma-chain-associated signaling pathway and by agglutination. Blood 98, 3346-3352. doi: 10.1182/blood.V98.1 2.3346

Tuszynski, G., Smith, M., Rothman, V., Capuzzi, D., Joseph, R., Katz, J., et al. (1992). Thrombospondin levels in patients with malignancy. Thromb. Haemost. 67, 607-611.

van Beijnum, J. R., Nowak-Sliwinska, P., Huijbers, E. J. M., Thijssen, V. L., and Griffioen, A. W. (2015). The great escape; the hallmarks of resistance to antiangiogenic therapy. Pharmacol. Rev. 67, 441-461. doi: 10.1124/pr.114.010215

Vernon-Wilson, E. F., Kee, W. J., Willis, A. C., Barclay, A. N., Simmons, D. L., and Brown, M. H. (2000). CD47 is a ligand for rat macrophage membrane signal regulatory protein SIRP (OX41) and human SIRPalpha 1. Eur. J. Immunol. 30, 2130-2137.

Wang, W., Zhang, E., and Lin, C. (2015). MicroRNAs in tumor angiogenesis. Life Sci. 136, 28-35. doi: 10.1016/j.lfs.2015.06.025

Watnick, R. S., Rodriguez, R. K., Wang, S., Blois, A. L., Rangarajan, A., Ince, T., et al. (2015). Thrombospondin-1 repression is mediated via distinct mechanisms in fibroblasts and epithelial cells. Oncogene 34, 2823-2835. doi: 10.1038/onc. 2014.228

Weng, T.-Y., Huang, S.-S., Yen, M.-C., Lin, C.-C., Chen, Y.-L., Lin, C.-M., et al. (2014). A novel cancer therapeutic using thrombospondin 1 in dendritic cells. Mol. Ther. 22, 292-302. doi: 10.1038/mt.2013.236

Williams, S. (2012). One Drug to Shrink All Tumors. Available at: http://news.sciencemag.org/health/2012/03/one-drug-shrink-all-tumors?ref=hp

Willingham, S. B., Volkmer, J.-P., Gentles, A. J., Sahoo, D., Dalerba, P., Mitra, S. S., et al. (2012a). The CD47-signal regulatory protein alpha (SIRPalpha) interaction is a therapeutic target for human solid tumors. Proc. Natl. Acad. Sci. U.S.A. 109, 6662-6667. doi: 10.1073/pnas.1121623109

Willingham, S. B., Volkmer, J.-P., Weiskopf, K., Ring, A. M., and Weissman, I. L. (2012b). Reply to soto-pantoja et al. and Zhao et al.: targeting CD47 on human solid tumors. Proc. Natl. Acad. Sci. U.S.A. 109, E2844-E2845. doi: 10.1073/pnas.1209743109

Wilson, F. H., Johannessen, C. M., Piccioni, F., Tamayo, P., Kim, J. W., Van Allen, E. M., et al. (2015). A functional landscape of resistance to ALK inhibition in lung cancer. Cancer Cell 27, 397-408. doi: 10.1016/j.ccell.2015.02.005

Xu, J.-F., Pan, X.-H., Zhang, S.-J., Zhao, C., Qiu, B.-S., Gu, H.-F., et al. (2015). Cd47 Blockade Inhibits Tumor Progression Human Osteosarcoma in Xenograft Models. Oncotarget 5. Available at: http://www.impactjournals.com/ oncotarget $/$ index.php?journal $=$ oncotarget $\&$ page $=$ article $\& o p=$ view $\&$ path $\% 5 B$ $\% 5 \mathrm{D}=4282$ [accessed July 8, 2015].

Xu, W., Kaneko, F. T., Zheng, S., Comhair, S. A. A., Janocha, A. J., Goggans, T., et al. (2004). Increased arginase II and decreased NO synthesis in endothelial cells of patients with pulmonary arterial hypertension. FASEB J. 18, 1746-1748. doi: 10.1096/fj.04-2317fje

Yao, M., Rogers, N. M., Csányi, G., Rodriguez, A. I., Ross, M. A., St. Croix, C., et al. (2014). Thrombospondin-1 activation of signal-regulatory protein- $\alpha$ stimulates reactive oxygen species production and promotes renal ischemia reperfusion injury. J. Am. Soc. Nephrol. 25, 1171-1186. doi: 10.1681/ASN.2013040433

Zhang, X., Galardi, E., Duquette, M., Lawler, J., and Parangi, S. (2005). Antiangiogenic treatment with three thrombospondin-1 type 1 repeats versus gemcitabine in an orthotopic human pancreatic cancer model. Clin. Cancer Res. 11, 5622-5630. doi: 10.1158/1078-0432.CCR-05-0459

Zhang, X., Kazerounian, S., Duquette, M., Perruzzi, C., Nagy, J. A., Dvorak, H. F., et al. (2009). Thrombospondin-1 modulates vascular endothelial growth factor activity at the receptor level. FASEB J. 23, 3368-3376. doi: 10.1096/fj.09-1 31649

Zhao, X. W., Matlung, H. L., Kuijpers, T. W., and van den Berg, T. K. (2012). On the mechanism of CD47 targeting in cancer. Proc. Natl. Acad. Sci. U.S.A. 109, E2843-E2843. doi: 10.1073/pnas.1209265109

Zhao, X. W., van Beek, E. M., Schornagel, K., Van der Maaden, H., Van Houdt, M., Otten, M. A., et al. (2011). CD47-signal regulatory protein- $\alpha$ (SIRP $\alpha)$ interactions form a barrier for antibody-mediated tumor cell destruction. Proc. Natl. Acad. Sci. U.S.A. 108, 18342-18347. doi: 10.1073/pnas.1106550108

Zheng, Y., Zou, F., Wang, J., Yin, G., Le, V., Fei, Z., et al. (2015). Photodynamic therapy-mediated cancer vaccination enhances stem-like phenotype and immune escape, which can be blocked by thrombospondin-1 signaling through CD47 receptor protein. J. Biol. Chem. 290, 8975-8986. doi: 10.1074/jbc.M114.624965

Conflict of Interest Statement: The authors declare that the research was conducted in the absence of any commercial or financial relationships that could be construed as a potential conflict of interest.

Copyright (c) 2015 Jeanne, Schneider, Martiny and Dedieu. This is an open-access article distributed under the terms of the Creative Commons Attribution License (CC BY). The use, distribution or reproduction in other forums is permitted, provided the original author(s) or licensor are credited and that the original publication in this journal is cited, in accordance with accepted academic practice. No use, distribution or reproduction is permitted which does not comply with these terms. 